\title{
Inhaled oxitropium bromide is currently used as the first-line therapy of patients with chronic pulmonary disease in Japan
}

\section{To the Editors:}

With great interest, we read the article by CAzzola et al. [1] concerning the airway responses to salmeterol in combination with another bronchodilator in patients with chronic obstructive pulmonary disease (COPD). The authors concluded that "a pretreatment with a conventional dose of oxitropium bromide (OTB) did not preclude the possibility of inducing a further bronchodilation with salbutamol in patients suffering from partially reversible COPD". Because inhaled OTB is widely used in treatment of patients with COPD in Japan [2-5], the results are clinically very important.

We basically agree with the authors that further bronchodilating responses to salbutamol were not always investigated by pretreatment with OTB in patients with COPD. However, several possibilities still exist. The dose of OTB was not sufficient to prevent a further bronchodilation to salmeterol in the patients. Unfortunately the anthropometric data were not presented in the article, so it is difficult to evaluate whether a $200 \mu \mathrm{g}$ of OTB was appropriate to elicit a maximal bronchodilation in the patients. It has been reported that OTB produces a dose-dependent increase of forced expiratory volume in one second (FEV1) in patients with COPD [6]. The other possibility is that the participants enrolled in the current study were asthmatic rather than stable COPD patients. Although anticholinergic drugs usually produce a greater bronchodilating response than $\beta_{2}$-adrenergic drugs in stable COPD patients [7], the current study contradicted that $\beta_{2}$-adrenergic agonists produced a better bronchodilation than anticholinergic inhalation. Because COPD is strictly differentiated from bronchial asthma in association with hyperresponsiveness to $\beta_{2}$-adrenergic stimulants, patients having $>20 \%$ reversibility on a $\beta$-adrenergic inhalational test were not determined as stable COPD patients. In the current study patients exhibited $\sim 48 \%$ reversibility by a $\beta$ adrenergic inhalational drug. COPD also increases in frequency with age and is found more frequently in patients aged 70-80 yrs. Thus, age effect on the bronchodilator responses to the agents may be important. Bronchodilator responses to $\beta_{2}$-adrenergic and/or anticholinergic inhalational drugs between younger and older patients with asthma or obstructive lung disease have been reported [3, $8,9]$. Impaired bronchodilator response to salbuterol was implicated in the elderly [9]. The age of patients in the current study, which was not mentioned in the article, may effect the airway responses to the bronchodilators.

COPD is a slow but progressive disease. The main purposes of the treatment for COPD are considered to be prevention of exacerbation of the disease, and the production of a significant bronchodilating effect to maintain lung function, and subsequently achieving a standard level of quality of life (QoL). The $\beta_{2}$-adrenergic agonists used to be the first-line bronchodilators for treatment of COPD. Although the current study demonstrated that an anticholinergic inhalation, OTB, did not produce a further bronchodilation with salbutamol in patients with COPD, the effects of other $\beta_{2}$-adrenergic agonists on airway responses to OTB may be more important. Because the pathogenesis of COPD is closely related to the bronchomotor tone, which is based on the sympathetic and parasympathetic balance [7], inhaled OTB has already been used as the first line therapy of COPD in Japan. However, many elderly patients with COPD are often untreated despite some reversibility of airways obstruction in response to the drugs. As the inhaled anticholinergic drug may well be beneficial in these individuals in terms of reducing symptoms and improving the QoL $[2-5,10]$, older patients with chronic airflow limitation may be treated with the inhaled anticholinergic drug alone or its combination with $\beta_{2}$ adrenergic agents.

\section{S. Teramoto, Y. Ouchi}

Dept of Geriatric Medicine, Faculty of Medicine, Tokyo University Hospital, 7-3-1- Hongo Bunkyo-ku, Tokyo 113-8655, Japan. Fax: 81358006530.

\section{References}

1. Cazzola M, Di Perna F, Noschese P, et al. Effects of formoterol, salmeterol or oxitropium bromide on airway responses to salbutamol in COPD. Eur Respir J 1998; 11: $1337-1341$.

2. Teramoto S, Fukuchi Y, Orimo H. Effects of inhaled anticholinergic drug on dyspnea and gas exchange during exercise in chronic obstructive pulmonary disease (COPD). Chest 1993; 103: 1774-1782.

3. Teramoto S, Fukuchi Y. Improvements in exercise capacity and dyspnoea by inhaled anticholinergic drug in elderly patients with chronic obstructive pulmonary disease. Age Ageing 1995; 103: 278-282.

4. Teramoto S, Matsuse T, Sudo E, et al. Long-term effects of inhaled anticholinergic drug on lung function, dyspnea, and exercise capacity in patients with chronic obstructive pulmonary disease. Intern Med 1996; 35: 772-778.

5. Teramoto S, Matsuse T, Ouchi Y, Fukuchi Y. Influence of one-year treatment period on responses to anticholinergic inhalation inpatients with chronic obstructive pulmonary disease. Curr Ther Res 1997; 58: 78-87.

6. Ikeda A, Nishimura K, Koyama H, Izumi T. Comparative dose-response study of three anticholinergic agents and fenoterol using a metered dose inhaler in patients with chronic obstructive pulmonary disease. Thorax 1995; 50: $62-66$

7. Gross NJ, Skorodin MS. Role of the parasympathetic 
system in airway obstruction to emphysema. $N$ Engl $J$ Med 1984; 311: 421-425.

8. Kradjan WA, Driesner NK, Abuan TH, Emmick G, Schoene RB. Effect of age on bronchodilator response. Chest 1992; 101: 1545-1551.

9. Connolly MJ, Crowley JJ, Charan NB, Nielson CP, Vestal
RE. Impaired bronchodilator response to albuterol in healthy elderly men and women. Chest 1995; 108: 401-406.

10. Hay JG, Stone P, Carter J, et al. Bronchodilator reversibility, exercise performance and breathlessness in stable chronic obstructive pulmonary disease. Eur Respir $J$ 1992; 5: 659-664.

\section{REPLY}

\section{From the authors:}

We thank S. Teramoto and Y. Ouchi for the interest they have taken in our work. Their letter raises some salient points that we would like to address.

The first point of S. Teramoto and Y. Ouchi is that the dose of oxitropium bromide (OTB) we used was not sufficient to produce a further than bronchodilation to salmeterol. We must stress that in our study [1] we did not evaluate the effects of salmeterol on airway responses to OTB, but rather the effects of OTB on airway responses to salbutamol. We agree that $200 \mu \mathrm{g}$ OTB, which is its conventional dose, might be considered an insufficient dose. In fact, it has been demonstrated that forced expiratory volume in one second (FEV1) reached a plateau only after administration of a cumulative dose of $600 \mu \mathrm{g}$ OTB in patients with COPD [2]. Besides, we have shown that $400 \mu \mathrm{g}$, but not $200 \mu \mathrm{g}$, OTB would approximate 50 $\mu \mathrm{g}$ salmeterol in terms of mean peak response, but salmeterol has a longer duration of action than OTB [3]. In any case, we must highlight that recent data of our group (M. Cazzola, unpublished data) seem to suggest that the inhalation of 400-600 $\mu \mathrm{g}$ OTB may be required to achieve a further bronchodilation when inadequate relief is obtained after $50 \mu \mathrm{g}$ salmeterol, but the use of $600 \mu \mathrm{g}$ OTB alone might obviate the need for combination therapy. Therefore, we actually trust that adequate dosing with an inhaled $\beta$-agonist or an anticholinergic agent can result in the entire possible bronchodilation (as measured by FEV1) and may obviate the need for combination therapy. In fact, addition of a second agent does not confer great additional benefit when the doses are increased to the top of the doseresponse curve and this finding is independent of the class of bronchodilator used [4, 5]. In effect, the amount of smooth muscle relaxation that can be achieved in any particular patient is limited and independent of the mechanism that induces bronchodilation [6]. Precisely, in chronic obstructive pulmonary disease (COPD) there is parenchymal destruction, which will lead to a decrease in airways size. This effect might not be totally due to intrinsic airways disease but rather by a loss of the forces that keep them open.

Their second point is the possibility that the participants enrolled in our study were asthmatic rather than stable COPD patients. We are convinced that our patients were suffering from COPD because all fulfilled the criteria proposed by the American Thoracic Society [7]. The acute improvement in flow rates of airways obstruction following the short-term administration of an inhaled bronchodilation is often used in both the clinical and research setting for distinguishing between asthma and COPD. The opinion of many researchers is that the absence of an increase in FEV1 of at least $15 \%$ from the initial value after an inhalation of a bronchodilator excludes the diagnosis of asthma, and the presence of such a change is specific, thereby ruling out other possibilities such as COPD. However, Kesten and ReBUCK [8] demonstrated that acute responses of FEV1 and forced vital capacity (FVC) following a standard dose of inhaled bronchodilator are neither sufficiently sensitive nor sufficiently specific to differentiate asthma from COPD purely on spirometric grounds. Moreover, there are times when the patient with asthma may have entirely normal respiratory flow rates and times when obstruction does not respond dramatically to the short-term administration of a bronchodilator [9]. We believe that the classification of patients as reversible or irreversible probably leads to significant undertreatment of patients with COPD. In fact, the implication of having irreversible airflow obstruction is that therapy will not be useful. On the contrary, many patients will respond to therapy over a longer period of time or to therapy administered with a different agent [10]. Thus, patients with irreversible COPD defined by acute improvement in FEV1 do not have fixed airflows and may be able to benefit from bronchodilator therapy. We highlight that recent British Thoracic Society guidelines [11] for management of COPD state that spirometric values should be measured before and after an adequate dose of inhaled $\beta_{2}$-agonist when testing airflow reversibility and, in fact, we have used a high cumulative dose of salbutamol. In any case, it is always important to bear in mind that there is difficulty in distinguishing, with certainty, the difference between subjects with COPD who may show a degree of reversibility and those older subjects with asthma whose reversibility airflow obstruction has become more fixed. There may also be mixtures of COPD and asthma which co-exist in any one patient.

Their third point is the need to treat the older patients with chronic airflow limitation with an inhaled anticholinergic drug or in combination with $\beta_{2}$-adrenergic agents. Our published data do not support the assumption that elderly patients suffering from COPD are less sensitive to action of $\beta_{2}$-agonists. In fact, we demonstrated that salmeterol was more potent than ipratropium bromide, although our study population was expressly chosen to include aged patients [12]. We must emphasize that it has been suggested that, whilst the function of $\beta_{2}$-receptors may become impaired with age, their responsiveness is nonetheless well preserved. This suggestion supports our opinion. All the recent findings with long-acting $\beta_{2}$-agonists raise the question of whether it is still correct to consider an anticholinergic drug as the bronchodilator 
therapy of first choice in the treatment of stable COPD. We [13] believe that long-acting $\beta_{2}$-agonists should be considered an alternative first choice option in the algorithm supplied by FERGUSON and CHERNIACK [14]. However, since those patients suffering from COPD with pre-existing cardiac arrhythmias under treatment with long-acting $\beta_{2^{-}}$ agonists could be at special risk of developing new arrhythmias or of aggravating pre-existing ones [15], the use of anticholinergic drugs is preferable in all COPD patients suffering from pre-existing cardiac arrhythmias and hypoxaemia, regardless of their age.

\section{Cazzola, M.G. Matera}

Unità di Farmacologia Clinica e Centro di Farmacologia Respiratoria, Fondazione "Salvatore Maugeri", IRCCS, Istituto di Riabilitazione, Veruno (NO), Italy. Fax: 39 0322830294.

\section{References}

1. Cazzola M, Di Perna F, Noschese P, et al. Effects of formoterol, salmeterol or oxitropium bromide on airway responses to salbutamol in COPD. Eur Respir J 1998; 11: $1337-1341$.

2. Ikeda A, Nishimura K, Koyama H, Izumi T. Comparative dose-response study of three anticholinergic agents and fenoterol using a metered dose inhaler in patients with chronic obstructive pulmonary disease. Thorax 1995; 50: 62-66.

3. Cazzola M, Matera MG, Di Perna F, Calderaro F, Califano C, Vinciguerra A. A comparison of bronchodilating effects of salmeterol and oxitropium bromide in stable chronic obstructive pulmonary disease. Respir Med 1998; 92: 354-357.

4. LeDoux EJ, Morris JF, Temple WP, et al. Standard and double dose ipratropium bromide and combined ipratropium bromide and inhaled metaproterenol in COPD. Chest 1989; 95: 1013-1016.

5. Easton PA, Jadue C, Dhingra S, Anthonisen NR. A comparison of the bronchodilating effects of a beta- 2 adrenergic agent (albuterol) and an anticholinergic agent (ipratropium bromide) given by aerosol or in sequence. $N$ Engl J Med 1986; 315: 735-739.

6. Karpel JP. Bronchodilator responses to anticholinergic and beta-adrenergic agents in acute and stable COPD. Chest 1991; 99: 871-876.

7. American Thoracic Society. Standards for the diagnosis and care of patients with chronic obstructive pulmonary disease. Am J Respir Crit Care Med 1995; 152: S72S120.

8. Kesten S, Rebuck AS. Is the short-term response to inhaled $\beta$-adrenergic agonist sensitive or specific for distinguishing between asthma and COPD? Chest 1994; 195: $1042-1045$.

9. Rebuck AS, Read J. Assessment and management of severe asthma. Am J Med 1971; 51: 788-798.

10. Cazzola M, Vinciguerra A, Di Perna F, Matera MG. Early reversibility to salbutamol does not always predict bronchodilation after salmeterol in stable chronic obstructive pulmonary disease. Respir Med 1998; 192: 1012-1016.

11. The COPD Guidelines Group of the Standards of Care Committee of the BTS. BTS guidelines for the management of chronic obstructive pulmonary disease. Thorax 1997; 52 (supp 5): S1-S28.

12. Matera MG, Cazzola M, Vinciguerra A, et al. A comparison of the bronchodilating effects of salmeterol, salbutamol and ipratropium bromide in patients with chronic obstructive pulmonary disease. Pulm Pharmacol 1995; 8: 267-281.

13. Cazzola M, Matera MG. Should long-acting $\beta_{2}$-agonists be considered an alternative first choice option for the treatment of stable COPD? Respir Med 1998; in press.

14. Ferguson GT, Cherniack RM. Management of chronic obstructive pulmonary disease. $N$ Engl J Med 1993; 320: 1017-1022.

15. Cazzola M, Imperatore F, Salzillo A, et al. Cardiac effects of formoterol and salmeterol in patients suffering from COPD with pre-existing cardiac arrhythmias and hypoxaemia. Chest 1998; 114: 411-415. 